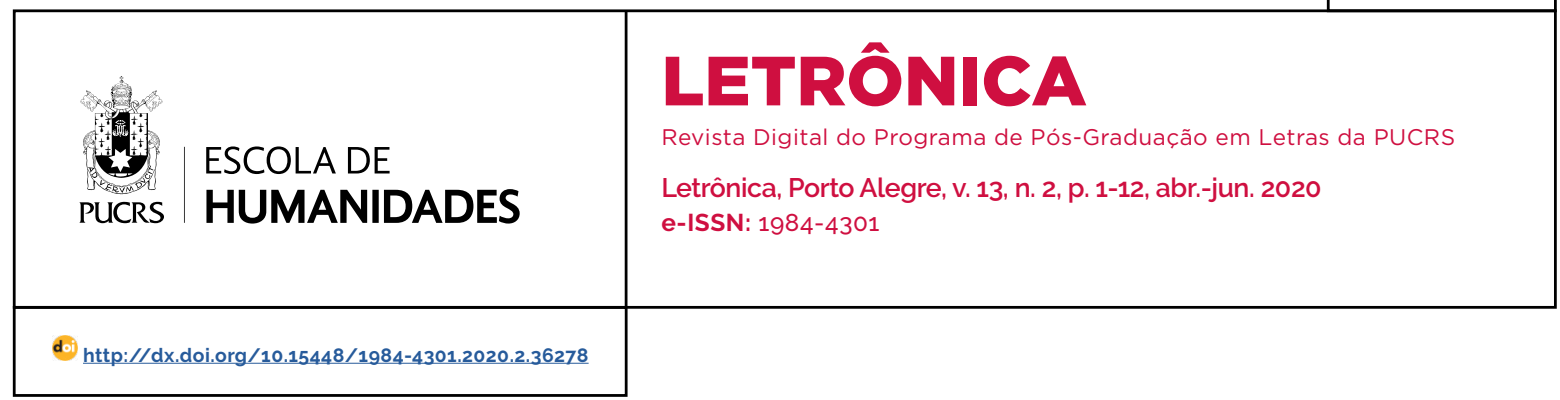

\title{
Eufemismo: um fenômeno multifacetado no cruzamento entre língua e cultura
}

\author{
Euphemism: a complex phenomenon between language and culture
}

Elisa Marchioro Stumpf orcid.org/0000-0002-9080-0903 elisa.stumpf@gmail.com

Recebido em: 6 nov. 2019. Aprovado em: 15 fev. 2020 Publicado em: 13 ago. 2020.
Resumo: O presente texto procura traçar um panorama dos estudos sobre o eufemismo, desde sua abordagem mais tradicional em gramáticas até chegar em perspectivas linguisticas que abordem seu funcionamento discursivo. Para isso, mostra-se a necessidade de tratar de temas como tabus/interdições e sua representação verbal, o disfemismo. Por conta dessa dupla abordagem, também se argumenta que ele é um fenômeno relevante para a compreensão de questões como (im)polidez e agressão verbal, além da linguagem politicamente correta. Como um mecanismo que se encontra relacionado com a questão das interdições sociais, seu estudo pode contribuir para a compreensão da relação entre língua e cultura a partir de perspectivas que descrevam seu funcionamento linguístico-discursivo nas atividades significantes dos sujeitos.

Palavras-chave: Eufemismos. Tabu. Figuras de linguagem. Lingua. Cultura.

Abstract: This text aims at drawing a panorama of studies about euphemism, from a more traditional approach found in grammars to linguistic perspectives that deal with its discursive functioning. In order to do so, it shows the need for treating subjects such as social taboos and its verbal representation, dysphemism. Because of this double approach, the text argues that euphemism is a relevant phenomenon to understand issues such as (im)politeness, verbal violence, and politically correct language. As it is a mechanism related to social taboos, its study may contribute to the understanding of the relationship between language and culture from perspectives that describe its linguistic and discursive functioning in the activities of the speakers.

Keywords: Euphemisms. Taboos. Figures of speech. Language. Culture.

\section{Introdução}

Discussões sobre a relação entre língua e cultura/sociedade se intensificaram no contexto brasileiro nos últimos anos, como consequência de certa exposição midiática e de maior debate acerca do tema. Como exemplo, citamos um caso ocorrido em 2012, quando o Ministério Público foi alvo de críticas ao ordenar a retirada de circulação do dicionário Houaiss, visto que este trazia uma acepção pejorativa (assim identificada) da palavra "cigano". De forma similar, mas mais voltado para o contexto escolar, tem se discutido o caráter racista de algumas obras de Monteiro Lobato (exemplo mencionado por Fiorin [2008]) e a sua adequação ao

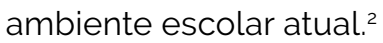

\section{(c) (1)}

Artigo está licenciado sob forma de uma licença Creative Commons Atribuição 4.0 Internacional.

\footnotetext{
1 Universidade Federal de Pelotas (UFPel), Pelotas, RS, Brasil..

Disponivel em: https://educacao.uol.com.br/noticias/2012/og/25/discussao-sobre-racismo-na-obra-de-monteiro-lobato-continua-hoje-em-reuniao-no-mec.htm. Acesso em: 8 abr. 2017.
} 
Esses exemplos apontam para o fato de que os falantes se dão conta de que a lingua não é um instrumento de comunicação neutro, o qual utilizamos com razoável maestria na vida cotidiana. De fato, o que está em jogo nos dois casos é o papel e a importância da lingua e das representações de grupos sociais, ou seja, a relação entre língua e cultura. Isso pode ser comprovado também pelo movimento a favor do politicamente correto, que surgiu "baseado na crença de que a língua que usamos influencia a maneira como pensamos"3 (OXFORD, 2005. p. 367, tradução nossa). De maneira geral, o movimento a favor da linguagem politicamente correta, preocupado com o fato de que algumas formas de expressão possam ofender e sugerir preconceito, oferece alternativas ao falante, na tentativa de evitar certos termos considerados pejorativos e ofensivos. Assim, defende-se que substituir palavras preconceituosas poderia ajudar a acabar com o preconceito.

Uma das saidas encontradas para isso é o eufemismo, visto que ele é motivado pela vontade ou necessidade de suavizar algumas palavras, de modo a não ofender o alocutário. De fato, seu uso aponta para uma interdição ao mesmo tempo em que mostra como o falante se "esquiva" dela. É necessário ressaltar, entretanto, que esse é um fenômeno multifacetado, objeto de muitas definições e abordagens, as quais estudaremos detalhadamente abaixo.

O objetivo deste texto 4 é buscar, em diferentes perspectivas, reflexões sobre o eufemismo e, posteriormente, cotejá-las com vistas a ressaltar suas contribuições para o estudo desse fenômeno. Partimos da classificação do eufemismo como uma figura de linguagem ou de pensamento, perspectiva bastante presente em obras de referência, como gramáticas utilizadas em diversos niveis de ensino. Em seguida, apoiamo-nos em estudos linguísticos mais recentes a fim de traçar um breve panorama dos mesmos, que tendem a ressaltar o papel do contexto e dos interlocutores na definição e análise de eufemismos. O recurso a diferentes perspectivas linguisticas leva-nos a constatar que, longe de ser apenas uma figura de linguagem restrita a usos mais rebuscados da língua, o que poderia ser facilmente inferido a partir da leitura das gramáticas, o eufemismo é um fenômeno que faz parte das enunciações comuns dos falantes em diversas situações. Além disso, as diversas pesquisas que tratam do eufemismo dizem respeito à relação entre língua, cultura e pensamento. Assim, podemos considerar esse fenômeno como um testemunho de como o locutor experiencia a relação entre língua e cultura. De fato, essa afirmação é corroborada por Jamet e Jobert ao afirmarem que "o estudo do eufemismo constitui assim uma porta de acesso privilegiada a uma dada cultura"5 (2010, p. 20, tradução nossa).

Utilizamos diferentes critérios para selecionar o corpus deste texto. Em primeiro lugar, consideramos a importância histórica de alguns textos. É o caso do tratado escrito por Dumarsais em 1730 e o livro de Correia (1927), esse por ser a primeira obra sobre eufemismos em língua portuguesa de que se tem conhecimento. Em segundo lugar, foi levada em consideração a pertinência de alguns textos como materiais de referência na área. Enquadram-se nesse critério o livro de Bonhomme (1998) sobre as figuras no discurso e as gramáticas de língua portuguesas cujos autores gozam de prestígio dentre os gramáticos brasileiros. Em terceiro lugar, buscamos apoio em estudos linguísticos realizados tanto no Brasil quanto no exterior. Para tanto, selecionamos estudos que pudessem representar diversas correntes da linguística que se debruçam sobre o tema, selecionandoos por sua atualidade e pertinência. No que diz respeito aos estudos estrangeiros, a grande parte dos trabalhos encontrados vêm do campo da pragmática e da linguística cognitiva. Especificamente no que tange ao contexto

\footnotetext{
Do original: based on the belief that the language we use influences the way we think

4 Este trabalho retoma e expande reflexões apresentadas na introdução e no primeiro capitulo da tese da autora (STUMPF, 2017), intitulada No limite do diálogo: eufemismo e enunciação em Émile Benveniste.

5 Do original: l'étude de l'euphémisme constitue donc une porte d'accès privilégiée à une culture donné.
} 
nacional, devemos ressaltar que uma pesquisa utilizando apenas "eufemismo" como palavrachave obteve poucos resultados em bases de dados brasileiras (fato que, por si só, já se constitui em um dado interessante). Para darmos prosseguimento ao nosso estudo, foi necessário ampliar a busca para temas relacionados, como tabu $^{6}$ e linguagem politicamente correta, para que fossem encontradas menções sobre o fenômeno em questão nas pesquisas linguísticas brasileiras atuais, o que justifica a inclusão dos trabalhos de Almeida (2007), Rajagopalan (2000), Fiorin (2008), Neves (2014) e Morato e Bentes (2017). Apresentamos, por fim, a nossa proposta (STUMPF, 2017), que procura formular uma descrição enunciativa para o eufemismo com base na obra do linguista Émile Benveniste.

O texto a seguir refaz o percurso investigativo realizado, iniciando com uma discussão sobre figuras de linguagem e tropos para, em seguida, trazer a classificação propostas por gramáticas brasileiras. Posteriormente, passamos aos estudos linguísticos mencionados acima e concluímos com as considerações tecidas a partir da análise do conjunto de nossa pesquisa.

\section{Figuras e tropos}

Inicialmente, podemos destacar uma abordagem que caracteriza o eufemismo como uma figura de linguagem. Ao pesquisarmos gramáticas e dicionários, constatamos que tal definição é bastante frequente. Entretanto, julgamos necessário, entender a inclusão do eufemismo nessa categoria e precisar melhor de que tipo de figura - um conceito em si mesmo complicado - se trata. Expomos, a seguir, um apanhado da pesquisa empreendida em tais materiais, que foi realizada com o intuito de buscar os seguintes aspectos: a) classificação proposta; b) definição; c) mecanismos de realização; e d) situações de uso, ainda que nem todas as fontes consultadas trouxessem todas as informações. Inicialmente, apresentamos os resultados de uma pesquisa sobre figuras de linguagem ou tropos e a classificação dos eufemismos, utilizando os autores Bonhomme (1998) e Dumarsais (1988); posteriormente, fazemos uma sintese das pesquisas realizadas em gramáticas da língua portuguesa.

De acordo com Bonhomme (1998, p. 7), os termos figura, tropo e imagem não são equivalentes. Para o autor, a figura estaria relacionada à retórica e diria respeito à expressividade do discurso em relação à língua padrão. Para que se possa caracterizar como uma figura, o autor propõe quatro características a serem preenchidas por uma palavra ou expressão:

1. ser uma forma discursiva marcada, percebida como algo especifico;

2. resultar da escolha de um locutor;

3. ser mensurável, na medida que sua repetição facilita seu reconhecimento;

4. melhorar o enunciado, graças aos seus efeitos (argumentativos, afetivos, estéticos etc.).

Para Bonhomme, o eufemismo é uma figura referencial, visto que o próprio de tais figuras diz respeito à relação entre linguagem e realidade. Nas palavras do autor (BONHOMME, 1998. p. 14, tradução nossa), "pouco marcadas nos enunciados e dificilmente isoláveis em elementos formais, elas são sinalizadas pelas diferenças que elas introduzem entre o discurso e seu contexto".7 Seguindo esse raciocínio, o eufemismo é definido pelo autor por meio de sua função de atenuar a expressão de realidades desagradáveis, instituindo, assim, uma diferença de intensidade entre a realidade e o discurso

Dessa forma, na proposta de Bonhomme, o eufemismo concentra dois atos de fala: em primeiro lugar, encontramos um ato moderador, que borra a realidade à qual se faz referência; em segundo

\footnotetext{
6 Embora seja um conceito recorrente neste texto, não teorizamos exaustivamente sobre tabus. Baseamo-nos em Freud, que explica que "tabu é uma palavra de origem polinésia cuja tradução nos causa dificuldades porque não temos mais o conceito designado por ela. [...] O significado do tabu se diferencia em duas direções opostas. Por um lado, significa 'sagrado', 'consagrado'; por outro, 'sinistro', 'perigoso', 'proibido', 'impuro'" (FREUD, 2013, p. 58, grifo do autor).

Do original: peu marquées dans les énoncés et difficilement isolables sur des éléments formelles, elles se signalent par les écarts qu'elles introduisent entre le discours et son contexte.
} 
lugar, deparamo-nos com um ato melhorativo, que minimiza essa realidade. Em relação aos mecanismos de realização, o linguista propõe o eufemismo como uma figura derivada, que recobre a) alguns tropos, como a metáfora; b) algumas figuras sintáticas, como a perifrase e c) figuras morfológicas, como a apócope e a epêntese.

O autor também discorre sobre as situações de uso dos eufemismos, distinguindo duas possibilidades. A primeira situação discursiva trazida refere-se à atenuação de tabus que surgem de interdições culturais, tais como doenças, morte, atos fisiológicos e sexuais. A segunda situação diz respeito à atenuação de problemas sociais, com destaque aos eufemismos utilizados na midia e na linguagem administrativa.

Dumarsais, gramático francês do século XVIII que publicou uma renomada obra intitulada Des tropes ou des différents sens, em 1730, classifica o eufemismo entre os tropos. Ao discorrer sobre figuras em geral, o autor faz uma crítica à ideia de que elas são uma maneira de falar distante da maneira cotidiana. Nas suas palavras, "não há nada de tão natural, de tão ordinário e de tão comum que as figuras na linguagem dos homens"8 (DUMARSAIS, 1988, p. 62, tradução nossa). Nessa obra, o gramático defende a ideia de que as figuras são próprias da linguagem humana e de que não é possivel falar sem utilizá-las.

De acordo com Dumarsais, os tropos seriam uma parte especifica das figuras, pois, por intermédio deles, as palavras assumem significações diferentes de sua significação própria9. Dentre as inúmeras possibilidades de utilização dos tropos, destaca-se seu uso para "disfarçar ideias duras, desagradáveis, tristes ou contrárias à modéstia"10 (DUMARSAIS, 1988, p. 77. tradução nossa), ressaltando aí os eufemismos. De fato, para o gramático, o eufemismo baseiase no disfarce de tais ideias sob nomes que não são seus nomes próprios. Nesse sentido, podemos pensar que o eufemismo funciona como uma espécie de véu, dando uma aparência mais agradável a ideias chocantes. O gramático (DUMARSAIS, 1988, p. 161) também menciona a ideia de que alguns eufemismos estão relacionados com uma superstição segundo a qual a simples pronúncia de uma palavra poderia atrair má sorte, o que ainda era possivel de se constatar em cerimônias religiosas, em que se evitava chamar entidades religiosas por algum nome que lhes era desagradável.

Ao comparar as considerações dos autores, podemos perceber uma discordância entre a classificação dos eufemismos como figura ou tropo. Bonhomme (1998), partindo de uma visão referencialista de sentido, classifica o eufemismo como uma figura que expressa uma diferença entre a linguagem e a realidade. Nessa perspectiva, o eufemismo seria uma figura de linguagem que marcaria uma discrepância entre o mundo real e a linguagem, visto que essa se encontra empregada de forma a atenuar o referente. Isso pode acontecer por meio de dois atos distintos: em primeiro lugar, há que se enfraquecer determinada realidade, para, em seguida, melhorá-la através das palavras utilizadas.

Para Dumarsais (1988), o eufemismo se encontra classificado como tropo, um tipo de figura cuja especificidade reside na diferença que se estabelece entre sentido próprio e sentido figurado. Aqui, não temos mais a relação entre linguagem e realidade, mas sim entre diferentes sentidos que uma mesma palavra pode assumir. Existiria, no entanto, uma correlação ideal entre as ideias e as palavras, correlação que pode ser quebrada por meio de eufemismos. Esses servem de véu, na medida que disfarçam uma ideia negativa sem, contudo, deixar de oferecer a possibilidade de entrevê-la.

\subsection{0 eufemismo visto pelas gramáticas brasileiras}

Quando nos voltamos às gramáticas brasileiras, constatamos que parece existir maior consenso na classificação e na definição do eufemismo. Todas

8 Do original: il n'y a rien de si naturel, de si ordinaire et de si commun que les figures dans le langage des hommes.

9 De acordo com Dumarsais (1988, p. 73), o sentido próprio de uma palavra é a sua primeira significação. O sentido figurado, por sua vez, decorre da utilização de uma determinada palavra com um outro sentido que não o primeiro.

10 Do original: déguiser des idées dures, désagréables, tristes, ou contraires à la modestie. 
as gramáticas pesquisadas classificam-no como uma figura de pensamento, embora apenas duas gramáticas digam o que entendem por isso. Na sua explicação, Azeredo (2008, p. 496) assume postura semelhante à de Bonhomme (1998), ao propor que "essas figuras manifestam seu rendimento no desacordo da relação de verdade entre o que se diz literalmente e a realidade da qual se fala". Percebemos também que todas as definições de eufemismo dizem respeito ao fenômeno enquanto processo, e não enquanto produto. Assim, podemos considerar que, para as gramáticas consultadas, o eufemismo é o ato de empregar uma expressão eufemística, e não a expressão em si.

O Quadro 1 apresenta um resumo aa pesquisa realizada. Nas gramáticas consultadas, há poucas menções sobre a motivação, o funcionamento e o uso de eufemismos. Na sua Moderna gramática portuguesa, Bechara faz referência aos tabus linguísticos, que podem favorecer o emprego de expressões eufemísticas, visto que o medo de proferir certas palavras ligadas à religião leva à desconfiguração voluntária das mesmas. Por sua vez, a Gramática Houaiss faz menção à contraparte do eufemismo, ou seja, o disfemismo, definindo-o como "uso de palavra ou expressão considerada grosseira, grotesca, nauseante ou simplesmente desagradável em lugar de outra mais branda ou neutra" (2008, p. 500).

Quadro 1 - Síntese do tratamento do eufemismo presente em gramáticas brasileiras

\begin{tabular}{ccc}
\hline Obra/Autor/ & \\
Data de publicação & Classificação proposta & Definição \\
\hline
\end{tabular}

Nossa gramática.

Luiz Antonio Sacconi (2010)

Figura de pensamento

Gramática normativa da língua portuguesa. Carlos Henrique da Rocha Lima (2005).

Gramática Houaiss da língua portuguesa. José Carlos de Azeredo (2008).

Novíssima gramática da língua portuguesa. Domingos Paschoal Cegalla (2008).

Moderna gramática portuguesa

Evalnildo Bechara (2004)
Figura de pensamento

Figura de pensamento - "o desvio se dá no sentido geral da frase, no entendimento total da linguagem. Essas figuras manifestam seu rendimento no desacordo da relação de verdade entre o que se diz literalmente e a realidade da qual se fala. Assim, é fundamental o conhecimento do referente, para a perfeita apreensão do sentido que se pretende atribuir ao enunciado" (p. 496)

Figuras de pensamento - "processos estilisticos que se realizam na esfera do pensamento, no âmbito da frase. Nelas intervêm fortemente a emoção, o sentimento, a paixão" (p. 626)

Causa que motiva a alteração semântica das palavras, o que ocorre quando "a palavra [não] guarda seu significado etimológico, isto é, originário [...] e assume valores novos" (p. 397) "emprego de palavras ou expressões agradáveis, em substituição às que tem sentido grosseiro e desagradável" (p. 532).

"é o meio pelo qual se evita uma palavra ou expressão molesta, odiosa ou triste, substituindo-a por outra palavra ou expressão menos desagradável" (p. 518).

"atenuação de um fato trágico, grosseiro ou desagradável por meio de expressões consideradas mais amenas" (p. 500).

"Consiste em suavizar a expressão de uma ideia triste, molesta ou desagradável, substituindo o termo contundente por palavras ou circunlocuções amenas ou polidas" (p. 626)

"translação de sentido pela suavização da ideia" (p. 399).

Fonte: Elaborado pela autora. 
Como algumas definições acima sugerem, o eufemismo estaria intimamente relacionado ao nivel lexical e ao processo de substituição de palavras. Entretanto, esses não são seus únicos mecanismos de funcionamento linguístico. Ademais, é preciso destacar que o eufemismo não é um mecanismo em si; ele pode se realizar por meio de inúmeros mecanismos, sendo que nenhum deles the é próprio. Há muitos estudos realizados sobre esse tema específico em lingua inglesa (JAMET, 2010; WARREN, 1992; TOURNIER, 1991). Warren (1992), por exemplo, diferencia quatro meios principais de formação de eufemismos: dispositivos de formação de palavras (dentre os quais se encontrariam siglas, onomatopeias e derivação, dentre outros); modificações fonêmicas (abreviações, uso de asteriscos ou outros sinais gráficos, rimas e substituições fonêmicas); palavras estrangeiras (em especial do francês e do latim) e inovações semânticas (particularização de termo, implicação de uma relação entre consequente e antecedente, metáforas, metonímias, ironias ou opostos, dentre outras). No entanto, tais tentativas de classificação são costumeiramente alvo de criticas, devido a dois motivos: a) a dificuldade de delimitar e diferenciar alguns mecanismos e b) a frequente possibilidade de presença simultânea de mais de um mecanismo empregado para formar um eufemismo. Além disso, a exaustividade das classificações não necessariamente ajuda a compreender o fenômeno.

Em português, entretanto, há poucas pesquisas dedicadas a eufemismos. Cabe mencionar, inicialmente, um trabalho dedicado ao estudo de eufemismos, intitulado "O eufemismo e o disfemismo no português moderno", de autoria de Heinz Kröll, publicado em 1984. Nessa obra, contudo, o autor apenas apresenta uma espécie de compilação de eufemismos divididos por temática (superstições, deficiências, decência, ofensas etc.), sem trazer nenhuma contribuição para o estudo do fenômeno em si, motivo pelo qual não a abordados aqui.

Destacamos, porém, um estudo bastante abrangente intitulado "O eufemismo e o disfemismo na língua e na literatura portuguesa", publicado em 1927. Nesse trabalho, o autor João da Silva Correia identifica vários "processos eufemizantes" (1927, p. 463), classificando-os entre aqueles que ocorrem no campo dos auxiliares da linguagem e nos campos lexical, fonético, gramatical e estilistico. O Quadro 2 procura resumir a extensa proposta do autor, sem esgotar as classificações trazidas em sua obra.

Quadro 2 - Sintese dos processos eufemizantes propostos por Correia (1927)

\begin{tabular}{|c|c|}
\hline $\begin{array}{l}\text { 1. Campo dos } \\
\text { auxiliares da } \\
\text { linguagem }\end{array}$ & $\begin{array}{l}1.1 \text { tom de voz } \\
1.2 \text { popismas } \\
1.3 \text { gestos }\end{array}$ \\
\hline & $\begin{array}{l}2.1 \text { elipse } \\
2.2 \text { substituição de fonemas } \\
2.3 \text { versão (emprego de palavras } \\
\text { estrangeiras) } \\
2.4 \text { termo científico } \\
2.5 \text { arcaismo } \\
2.6 \text { onomatopeias }\end{array}$ \\
\hline $\begin{array}{l}\text { 2. campo } \\
\text { lexical }\end{array}$ & $\begin{array}{l}\text { 2.7 vocábulos da linguagem infantil } \\
2.8 \text { interpretação vocabular } \\
2.9 \text { formas primitivas } \\
2.10 \text { formas derivadas } \\
2.11 \text { formas compostas } \\
2.12 \text { denominações afetuosas } \\
2.13 \text { termos genéricos (incluindo } \\
\text { uso de pronomes) }\end{array}$ \\
\hline & $\begin{array}{l}3.1 \text { redução } \\
3.2 \text { encorpamento (adição de } \\
\text { fonemas) }\end{array}$ \\
\hline $\begin{array}{c}\text { fonético } \\
\text { (deformação) }\end{array}$ & $\begin{array}{l}\text { 3.3 deslocamento prosódico } \\
3.4 \text { mutação de fonemas } \\
3.5 \text { inversão dos sons } \\
3.6 \text { cruzamentos vocabulares }\end{array}$ \\
\hline & $\begin{array}{l}4.1 \text { mudança de gênero } \\
4.2 \text { mudança de número }\end{array}$ \\
\hline $\begin{array}{l}\text { 4. Campo } \\
\text { gramatical }\end{array}$ & $\begin{array}{l}4.3 \text { mudança de modos } \\
4.4 \text { mudança de tempos } \\
4.5 \text { mudança de forma proposicional } \\
4.6 \text { alianças vocabulares }\end{array}$ \\
\hline & $\begin{array}{l}5.1 \text { metonimia } \\
5.2 \text { metáfora }\end{array}$ \\
\hline $\begin{array}{l}\text { 5. Campo } \\
\text { sematológico }\end{array}$ & $\begin{array}{l}5.3 \text { alegoria } \\
5.4 \text { antifrase } \\
5.5 \text { trocadilho } \\
5.6 \text { etimologia popular }\end{array}$ \\
\hline & $\begin{array}{l}6.1 \text { circunlocução } \\
6.2 \text { hipersemia }\end{array}$ \\
\hline $\begin{array}{l}\text { 6. Campo } \\
\text { estilistico }\end{array}$ & $\begin{array}{l}6.3 \text { hipossemia } \\
6.4 \text { expressão negativa } \\
6.5 \text { frase paradoxal } \\
6.6 \text { repetição }\end{array}$ \\
\hline
\end{tabular}

Fonte: Elaborado pela autora. 
O próprio autor admite que tal classificação não contempla o fenômeno na sua complexidade e aponta para a dificuldade de definir as fronteiras entre esses fenômenos. Para nosso estudo, mais interessante do que somente listar os procedimentos linguísticos por meio dos quais se realiza o eufemismo é tentar entender o seu funcionamento discursivo, dado que muitos autores, mais recentemente, postulam que tal fenômeno só pode ser apreendido em uma determinada situação de discurso.

\section{0 eufemismo visto pela linguística}

Conforme demonstramos, muitas pesquisas focalizam apenas os mecanismos linguísticos de produção de eufemismos, compreendendo-o como um fenômeno que ocorre basicamente em nível lexical e é empregado para substituição de palavras ou expressões consideradas inadequadas para o uso linguístico por equivalentes mais amenizados ou indiretos. Outras pesquisas, entretanto, procuram dar conta do seu funcionamento em situações reais de uso. Tais pesquisas tendem a ressaltar o papel do interlocutor, tanto na produção do eufemismo - na medida em que ele é um dos fatores que determinam seu uso - quanto na recepção, já que o alocutário deve ser capaz de recuperar a ideia à qual o locutor faz alusão.

Essa perspectiva está relacionada com pesquisas de orientação pragmática, que consideram o eufemismo em termos de face, ligado a questões de polidez ${ }^{11}$ e estilo e sujeito a convenções sociais do contexto pragmático onde ele ocorre (CASAS GÓMEZ, 2009). Pensar o eufemismo a partir de uma perspectiva pragmática leva-nos a colocar em relevo: a) suas características discursivas; b) os elementos que estão em jogo no processo de comunicação; c) o papel interpretativo do ouvinte; e d) os efeitos perlocucionários que nele podem ser produzidos pelos eufemismos. Definições como a de Allan e Burridge ${ }^{12}$ (1991) mostram a importância de questões de preservação de face, tanto do locutor quanto do interlocutor, enquanto outras relacionam o fenômeno às máximas de cortesia ${ }^{13}$, visto que o emprego de eufemismos seria uma forma de respeitar o direito do ouvinte de não ser incomodado (ALCARAZ VARÓ; MARTÍNEZ LINARES, 1997 apud CASAS GÓMEZ, 2009, p. 733). Contudo, a grande contribuição das definições advindas da pragmática é que elas salientam a importância de se considerar o contexto no qual se situam os interlocutores, visto que o eufemismo, enquanto fenômeno discursivo, é motivado por fatores sociais, e o seu sucesso, segundo essa perspectiva, depende do reconhecimento da intenção do locutor pelo alocutário.

Essa ideia é corroborada por Jamet e Jobert (2010, p. 19, tradução nossa), quando afirmam que "o eufemismo não existe em si mesmo, pois é somente no reconhecimento pelo coenunciador que ele surge"14. Isso leva os autores a defender uma abordagem que considera a dimensão intersubjetiva desse fenômeno. Propor a existência de tal dimensão no uso de eufemismos significa que seu funcionamento depende dos interlocutores e, especialmente, da interpretação feita pelo alocutário. Assim, o que alguns autores chamam de "efeito eufêmico" (MÉLIS, 2010, p. 55) se localiza na recepção do enunciado, pois é o alocutário quem decide, em última instância, a respeito de como interpretar uma mensagem.

Esse raciocínio, a nosso ver, pode levar a uma consequência bastante relevante. Se concordamos que diferentes alocutários possam

\footnotetext{
11 Ressaltamos, entretanto, a observação de Culpeper (2018), segundo a qual as teorias sobre polidez deixam praticamente intocadas as questões de linguagem tabu e eufemismos.

12 Para os autores, eufemismos são palavras utilizadas de forma a evitar a perda de face, seja pelo locutor, pelo ouvinte ou ainda por uma terceira pessoa. Eles se diferenciam dos ortofemismos (que seriam as formas mais diretas e "neutras" e ficariam entre os eufemismos e os disfemismos) por serem mais coloquiais e/ou figurativos (indiretos) (ALLAN; BURRIDGE, 1991).

13 Lakoff (1973 apud SILVA, 2008, p. 171), em uma releitura de Grice, postula regras de cortesia cuja finalidade seria evitar conflitos em uma troca verbal. As regras podem ser resumidas em três máximas: 1) não imponha!, a qual implica que o locutor não deve ser autoritário em relação ao interlocutor; 2) ofereça alternativas, de forma que o interlocutor tenha liberdade para interpretar a mensagem e 3) seja amigável, que diz respeito ao fato de deixar o interlocutor confortável durante a interação. De acordo com Silva (2008, p. 171), o uso de eufemismo encontra-se relacionado à segunda regra e "tem o objetivo de dar ao interlocutor a opção de não entender e, assim, optar por outra interpretação da mensagem".

14 Do original: l'euphémisme n'existe plus en soi car c'est seulement dans la reconnaissance par le co-énonciateur qu'il prend vie.
} 
entender um enunciado de maneira distinta, restaria afirmar que não há eufemismos puros, pois tal interpretação depende de um contexto situacional delimitado. Disso, poderia resultar a conclusão de que seria impossivel elaborar dicionários de eufemismos, como vemos frequentemente em inglês e, mais recentemente, em português. Existem eufemismos que, de tão usados em uma determinada cultura, podem já ser considerados como lexicalizados, o que poderia retirar o seu "efeito eufêmico" em uma dada situação de uso. De acordo com Jamet (2010, p. 34, tradução nossa), "os eufemismos muito lexicalizados tornam-se frequentemente clichês, e se transformam em simples termos quase sinonimicos, geralmente com uma simples variação de registro e/ou de nível de língua". ${ }^{15}$

Além disso, considerar a dimensão intersubjetiva também implica dar valor a aspectos sociais e culturais, visto que as interações linguísticas não se dão em um vácuo. Assim, consideramos o eufemismo como um fenômeno privilegiado, porque favorece o estudo conjunto de língua e cultura, na medida em que evidencia como cada lingua interpreta a sociedade. Isso explica, por exemplo, o uso de eufemismos para realizar críticas sociais, pois o efeito provocado (muitas vezes, irônico), é mais bem aceito socialmente do que uma crítica direta. Além disso, o eufemismo é um vestígio daquilo que é considerado tabu em uma determinada cultura, uma vez que os locutores só atenuam aquilo que eles acreditam não poderem falar de forma "crua".

\subsection{A presença do eufemismo em pesquisas linguisticas brasileiras}

Em se tratando de pesquisas da área da linguística, podemos constatar que esse tema parece ainda não ter recebido a devida atenção no cenário brasileiro. Em primeiro lugar, vale mencionar que encontramos algumas pesquisas sobre a contraparte do eufemismo, o tabu linguístico. A mais antiga que descobrimos foi a realizada por R. F. Mansur Guérios, intitulada Tabus linguísticos (a nota da primeira edição, assinada pelo autor, data de 1955). Nela, o autor conceitua brevemente seu objeto de estudo e faz uma classificação de diferentes tipos de tabu. Devemos também ressaltar o estudo de Preti (1983) sobre a linguagem obscena no Rio de Janeiro do início do século $X X$. Partindo de uma perspectiva sociolinguística, o autor entende o léxico como um reflexo das atitudes sociais e mostra quais os mecanismos pelos quais se configurava a linguagem erótica, dentre eles o eufemismo.

Mais recentemente, pesquisas sobre tabus linguísticos podem ser encontrados no âmbito da dialetologia. A título de exemplo de tais estudos, citamos o trabalho de Almeida (2007), que analisa atlas linguísticos brasileiros a fim de propor uma tipologia dos tabus presentes, selecionando seis campos semânticos (fenômenos atmosféricos, corpo humano, religião e crenças, doenças, ciclos da vida e convívio e comportamento social) e mostrando as formas de substituição das palavras tabus encontradas nos atlas analisados. A autora conceitua tabu como "o termo ou a expressão que é, de certa forma, evitada e não deve ser proferida por se acreditar que tenha o poder de causar-lhe algum malefício" (2007, p. 28). Ao analisar os atlas, Almeida procurou identificar as formas pelas quais os tabus são referidos, a saber, eufemismos, disfemismos, diminutivos, formas neutras, expressões genéricas, particularidades físicas, metonímia e metáfora. 0 eufemismo figura, portanto, como um dos meios que possibilita aos sujeitos falarem de um tópico considerado tabu sem empregarem palavras consideradas desagradáveis.

O eufemismo também é mencionado em artigos sobre a linguagem politicamente correta, de autoria de alguns linguistas brasileiros importantes. Rajagopalan (2000) problematiza os ataques que esse tipo de discurso tem sofrido no debate público sobre o tema no Brasil, questionando-se o porquê de tantos sentimentos negativos ligados ao politicamente correto. Para sustentar seu argumento, o linguista recusa a ideia segundo a qual as palavras e as coisas estão

15 Do original: les euphémismes très lexicalisés deviennent souvent des clichés, et se transforment en simples termes (quasi) synonymiques, avec généralement une simple variation de registre et/ou de niveau de langue. 
em uma relação de arbitrariedade e propõe que a linguagem age sobre o mundo. De acordo com essa visão performativa, a modificação de certas expressões linguisticas é uma necessidade e, na opinião do autor, uma arma fundamental, ainda que insuficiente se solitária, na luta contra os preconceitos sociais. Dessa forma, Rajagopalan (2000) afirma que o eufemismo é um recurso linguístico que mostra como os falantes dão mais valor à língua e às palavras do que dariam caso houvesse um vínculo de natureza arbitrária entre lingua e referente. $O$ autor entende que, ao eufemismo, subjaz a ideia de que as palavras têm o poder de descrever o mesmo objeto de maneira diferente, mudando a percepção que o falante tem do referente.

Encontramos um posicionamento um pouco contrastante em Fiorin (2008). Segundo o linguista, a ideia de reformar o vocabulário a fim de evitar a transmissão de preconceitos é válida, desde que sejam respeitados alguns princípios do funcionamento da língua, sob a pena de ver os esforços em tal empreitada revelarem-se inúteis. De acordo com o linguista, nessa busca por outras palavras, o eufemismo aponta para os preconceitos existentes em uma sociedade, de forma que as novas palavras terminam por ser contaminadas por tais posturas discriminatórias ${ }^{16}$. Embora seja necessário deixar de usar termos "fortemente identificados com atitudes racistas, machistas etc.", o autor considera que "não basta mudar a linguagem para que a discriminação deixe de existir" (FIORIN, 2008, p. 3).

Neves (2014) complexifica a abordagem do assunto ao diferenciar enunciados que contêm formas consideradas incorretas politicamente, mas cuja enunciação é polida, daqueles que apresentam polidez na forma, mas incorreção enunciativa. A motivação da autora é o caso de uma das acepções da palavra cigano presente no dicionário Houaiss, sob acusação de ser preconceituosa contra o grupo que designa. A autora conclui que, enquanto certos usos linguísticos têm sido condenados por trazerem palavras relacionadas a visões ideológicas negativas, há outros casos de agressividade que passam despercebidos por conta de uma suposta moldura de polidez.

Morato e Bentes (2017), em dossiê específico sobre linguagem politicamente correta, retomam alguns dos estudos aqui mencionados no seu apanhado sobre o assunto, que vai além da perspectiva linguística e englobam a dimensão política do fenômeno. Elas completam sua exposição com a apresentação de uma perspectiva sociocognitiva para propor duas interpretações sobre o fenômeno que, segundo as autoras, pode ser entendido em um sentido fraco e um forte. $O$ primeiro diz respeito ao fato de que seu uso está relacionado a uma tentativa de exibir e promover reflexividade dos sujeitos no que tange à forma de produzir categorizações e/ou enunciados, ao passo que o segundo envolve o apoio a e o desenvolvimento de "regimes simbólicos que superem situações de desigualdades, preconceito e injustiça social" (MORATO; BENTES, 2017, p. 26). Tais características do politicamente correto estariam "conjugadas nas ações sociais de construção de novos ordenamentos, mais justos, democráticos e pluralistas" (MORATO; BENTES, 2017, p. 26).

Por fim, em nosso trabalho (STUMPF, 2017), procuramos desenvolver uma explicação do eufemismo segundo uma perspectiva enunciativa, tal como proposta por Émile Benveniste. Ao reler a obra do autor a partir de um ponto de vista que a toma como uma teoria da linguagem, discernimos duas abordagens do eufemismo. A primeira encontra-se exemplificada no texto "Eufemismos antigos e modernos" (BENVENISTE, 1949/2005). Nela, vemos manifestada a relação de intepretância, que coloca a língua em posição de primazia em relação aos demais sistemas semiológicos, no caso, a sociedade. As análises feitas pelo linguista mostram como a lingua interpreta a sociedade e determinados aspectos culturais, trazendo um

16 Esse fenômeno, recorrente nos estudos sobre eufemismo, é nomeado por Steven Pinker (2003) de euphemism treadmill ou "esteira de eufemismo". Ele consiste no fato de que a palavra utilizada como eufemismo para se referir a algo tabu acaba sendo contaminada por esse tabu e passa a ser um disfemismo, sendo substituida, dessa forma, por outro eufemismo que, por sua vez, sofrerá o mesmo processo e assim sucessivamente. 
testemunho das suas interdições nas formas de que ela dispõe para contorná-las.

A segunda forma de abordar o eufemismo surge a partir das considerações feitas em "A blasfemia e a eufemia" (BENVENISTE, 1969/2006), que tratam da relação entre lingua e locutor sob o viés das interdições culturalmente impostas. Ambos os fenômenos são analisados pelo linguista de maneira conjunta a fim de mostrar as consequências linguisticas das interdições na constituição do sujeito e o que isso diz do funcionamento da língua no meio social. A blasfemia diz respeito à transgressão do tabu de pronunciar o nome de Deus, motivada em situações em que o sujeito é fortemente tomado por emoções. A eufemia, por sua vez, é o processo por meio do qual o falante evita dizer aquilo que é interdito e "faz alusão a uma profanação da linguagem, mas sem realizála" (BENVENISTE, 2006, p. 262). Por meio de determinadas modificações, a palavra dita aponta para a realização de uma atenuação, disfarçando a profanação, ainda que preencha a função psiquica da transgressão para o locutor.

\section{Considerações finais}

Cotejando o que é exposto em gramáticas com as pesquisas linguísticas, podemos fazer algumas generalizações a respeito do eufemismo. Em primeiro lugar, e de forma a contrastar com o senso comum sobre o assunto (fortemente influenciado pelas gramáticas utilizadas na escola), o eufemismo não consiste em uma forma mais rebuscada de falar, que seria reservada a um uso mais estilistico e consciente (na literatura, por exemplo), fazendo-se presente na linguagem ordinária. Até mesmo a pesquisa de Dumarsais (1988), que trata o fenômeno como uma figura de linguagem, chama a atenção para o fato de que seu uso é algo corrente na língua comum. Além disso, sua classificação como figura de linguagem encontrada nas gramáticas brasileiras não ajuda a iluminar o fenômeno e a sua compreensão.

Em segundo lugar, considera-se que o eufemismo tem sua motivação nos tabus e nas interdições sociais, não sendo possivel estudá-lo separadamente das palavras e/ou expressões consideradas disfemísticas, ou seja, formas pouco polidas e até mesmo ofensivas para se referir a algum tabu.

No que tange à sua realização, vimos que não se trata de uma simples substituição por uma palavra sinônima, mas sim de um processo de atenuação de uma ideia desagradável e, dessa maneira, uma outra forma de conceitualizar a realidade, o que leva muitos autores a enxergá-lo como uma espécie de véu que propositalmente encobriria associações menos desejáveis. Ademais, ele não está restrito ao nível lexical, realizandose em vários níveis linguísticos e empregando até mesmo recursos extralinguísticos, como a entonação. Disso decorre também que o eufemismo não emprega mecanismos próprios na sua realização, podendo se dar por meio de inúmeras maneiras (metáforas, uso de siglas, modificações fonéticas, subentendidos etc.) conforme descrito por Warren (1992).

Também mostramos como sua compreensão envolve a consideração de aspectos culturais e intersubjetivos, pois cada cultura recorta suas interdições de maneira diferente. Dessa forma, o que é um tabu em uma cultura não o é, necessariamente, em outra. Além disso, os estudos advindos da pragmática mostram a necessidade de reconhecimento do eufemismo pelo alocutário, deslocando a realização do eufemismo do polo do emissor para o do receptor.

Por fim, trouxemos um breve apanhado de pesquisas que tematizam fenômenos linguísticodiscursivos bastante relevantes na discussão sobre língua e cultura, a saber, a violência, a (im) polidez e a (des)cortesia verbais e, de forma mais destacada neste artigo, a linguagem politicamente correta. A discussão desse último fenômeno parece apontar para a ideia de que tudo não se pode dizer na nossa atividade social enquanto sujeitos falantes, pois as palavras que empregamos têm consequências potencialmente negativas na construção de discursos e imaginários coletivos sobre determinados grupos sociais. Em muitos desses casos, entra em jogo o eufemismo, que aponta simultaneamente para a transgressão de um tabu, ou seja, uma ação com potencial de 
ofender, e o modo de contorná-lo linguística e discursivamente. É também o que pensa Mélis (2010, p. 51, tradução nossa) ao defender que o eufemismo "permite simultaneamente contornar e convocar o termo particular que supostamente designa mais adequada e diretamente a realidade em questão".17

Assim, de acordo com essa última visada, propomos que o eufemismo é um fenômeno complexo e multifacetado, que está no cerne da relação língua e cultura. Com seu duplo mecanismo, ele permite a abordagem dessa relação pelo viés da interdição, o que também é fundamental para as descrições do funcionamento social da língua, pois "o que uma cultura proíbe a caracteriza ao menos tanto quanto aquilo que prescreve" (BENVENISTE, 2005, p. 32). Dessa forma, reclamamos um lugar de destaque para o eufemismo, revendo sua tradicional classificação para avançar no estudo do seu funcionamento nas atividades significantes dos sujeitos que, constantemente, marcam e constroem sua relação com a sociedade e com a cultura na e pela língua.

\section{Referências}

ALMEIDA, Laura de. À guisa de uma tipologia dos tabus linguisticos: proposta para um glossário. 2007. 372 f. Tese (Doutorado em Linguística) - Programa de Pós-Graduação em Semiótica e Linguistica Geral, Universidade de São Paulo, São Paulo, 2007.

AZEREDO, José Carlos de. Gramática Houaiss da lingua portuguesa. São Paulo: Publifolha, 2008.

BECHARA, Evanildo. Moderna gramática portuguesa 37. ed., rev. e ampl. Rio de Janeiro: Lucerna, 2004.

BENVENISTE, E. Problemas de linguistica geral I. 5. ed. Campinas: Pontes, 2005

BENVENISTE, E. Problemas de linguistica geral II. 2. ed. Campinas: Pontes, 2006.

BONHOMME, Marc. Les figures clés du discours. Paris: Seuil, 1998

CASAS GÓMEZ, Miguel. Towards a new approach to the linguistic definition of euphemism. Language Sciences, v. 31, n. 6, p. 725-739, 2009

CEGALLA, Domingos Paschoal. Novissima gramática da lingua portuguesa. 48. ed. São Paulo: Nacional, 2008.
CORREIA, João da Silva. O eufemismo e o disfemismo na lingua e na literatura portuguesa. Lisboa: Arquivo da Universidade de Lisboa, 1927.

CULPEPER, Jonathan. Taboo language and impoliteness. In: ALLAN, Keith (ed.). The Oxford Handbook of Taboo Words and Language. Oxford, UK: Oxford University Press, 2018. https://doi.org/10.1093/oxfor$\mathrm{dhb} / 9780198808190.013 .2$

DUMARSAIS, C. C. Des tropes ou des différents sens. Paris: Flammarion, 1988.

FIORIN, José Luiz. A linguagem politicamente correta. Linguasagem (São Paulo), v. 1, p. 1-4, 2008.

FREUD, Sigmund. Totem e tabu. Porto Alegre: L\&PM Editores, 2013.

GUÉRIOS, R. F. M. Tabus linguísticos. 2. ed. São Paulo: Editora Nacional; Curitiba: Editora da Universidade Federal do Paraná, 1979.

JAMET, Denis. Historique et procédés linguistiques de l'euphémisme. In: JAMET, Denis; JOBERT, Manuel. Empreintes de l'euphémisme. Paris: L'Harmattan, 2010. p. 31-50.

JAMET, Denis; JOBERT, Manuel. Juste un petit mot sur l'euphémisme. In: JAMET, Denis; JOBERT, Manuel. Empreintes de l'euphémisme. Paris: L'Harmattan, 2010. p. 31-50

KRÖLL, Heinz. O eufemismo e o disfemismo no português moderno. Lisboa: Instituto de Cultura e Lingua Portuguesa, 1984.

LIMA, Rocha. Gramática normativa da língua portuguesa. 44. ed. Rio de Janeiro: J. Olympio, 2005.

MORATO, E.; BENTES, A. C. "O mundo tá chato": algumas notas sobre a dimensão sociocognitiva do politicamente correto na linguagem. Revista USP, n. 115, p. 11-28, 9 dez. 2017. https://doi.org/10.11606/ issn.2316-9036.voi115p11-28

MÉLIS. Gérard. L'euphémisme en syntaxe: le cas de la modalité d'apparence en anglais contemporain. In: JAMET, Denis; JOBERT, Manuel. Empreintes de l'euphémisme. Paris: L'Harmattan, 2010. p. 31-50.

NEVES, Maria Helena de Moura. Do "politicamente correto" ao incorretamente polido. DELTA, São Paulo, v. 30, n. 1, p. 137-160, 2014. https://doi.org/10.1590/ S0102-44502014000100008

OXFORD guide to British and American culture: for learners of English. Oxford: Oxford University Press, 2005

PINKER, Steven. The blank slate: the modern denial of human nature. Nova lorque: Penguin, 2003.

PRETI, Dino. A linguagem proibida: um estudo sobre a linguagem erótica. São Paulo: T. A. Queiroz, 1983.

\footnotetext{
${ }_{17}$ Do original: permet simultanément de contourner et de convoquer le terme particulier qui est censé désigner plus adéquatement et plus directement la réalité en question.
} 
RAJAGOPALAN, K. Sobre o porquê de tanto ódio contra a linguagem "politicamente correta". In: SILVA, F. L. da; MOURA, H. M. M. (org.). O direito à fala: a questão do preconceito lingüistico. Florianópolis: Ed. Insular, 2000. p. 93-102.

SACCONI, Luiz Antônio. Nossa gramática completa teoria e prática. 30. ed., rev. São Paulo: Nova Geração, 2010

SAUSSURE, F. Curso de Linguística Geral. São Paulo: Cultrix, 1975.

SILVA, Luiz Antônio da. Cortesia e formas de tratamento. In: PRETI, Dino. Cortesia verbal. São Paulo: Humanitas, 2008. p. 157-192.

STUMPF, Elisa Marchioro. No limite do diálogo: eufemismo e enunciação em Émile Benveniste. 2017. 118 f. Tese (Doutorado em Estudos da Linguagem) Instituto de Letras, Programa de Pós-Graduação em Letras, Universidade Federal do Rio Grande do Sul, Porto Alegre, 2017.

TOURNIER, Jean. L'expression euphémique des tabous. Recherches en linguistique étrangère II Annales litteráires de l'Université de Besançon, n. 167. p.151-177, 1991.

WARREN, Beatrice. What euphemisms tell us about the interpretation of words. Studia linguistica, v. 46, n 2, p.128-172, 1992.

\section{Elisa Marchioro Stumpf}

Professora adjunta de Português como lingua adicional na Universidade Federal de Pelotas (UFPel), Pelotas, RS, Brasil.

\section{Endereço para correspondência}

Elisa Marchioro Stumpf

Centro de Letras e Comunicação - UFPel

Rua Gomes Carneiro, 1, Bloco B, Andar Térreo

96010-610

Pelotas, RS, Brasil 